\title{
The last year of life for patients dying from cancer vs. non-cancer causes: a retrospective cross-sectional survey of bereaved relatives
}

\author{
Alina Kasdorf ${ }^{1}$ (1) . Gloria Dust ${ }^{1} \cdot$ Stefanie Hamacher ${ }^{2} \cdot$ Nicolas Schippel $^{1} \cdot$ Christian Rietz $^{3} \cdot$ Raymond Voltz $^{1,4,5,6}$. \\ Julia Strupp ${ }^{1}$. on behalf of CoRe-Net
}

Received: 30 September 2021 / Accepted: 10 February 2022 / Published online: 21 February 2022

(c) The Author(s) 2022

\begin{abstract}
Purpose To compare health care experiences of patients with cancer or non-cancer diseases in their last year of life. Methods A cross-sectional post-bereavement survey was conducted using an adapted German version of the VOICES questionnaire (VOICES-LYOL-Cologne). Differences in the reported experiences were assessed using a two-sided Pearson's chi-square test and Mann-Whitney $U$ test.

Results We collected data from 351 bereaved relatives. More than half of non-cancer patients were not informed that their disease could lead to death $(p<0.001)$. When this was communicated, in $46.7 \%$ of non-cancer and $64.5 \%$ of cancer patients, it was reported by the hospital doctor $(p=0.050)$. In all, $66.9 \%$ of non-cancer and $41.6 \%$ of cancer patients were not informed about death being imminent $(p<0.001)$. On average, non-cancer patients had significantly fewer transitions and hospital stays in their last year of life ( $p=0.014 ; p=0.008$, respectively). Non-cancer patients were treated more often by general practitioners, and cancer patients were treated more often by specialists ( $p=0.002 ; p=0.002$, respectively). A substantially lower proportion of non-cancer patients were treated by at least one member of or in the setting of general or specialized palliative care $(p<0.001)$.

Conclusions Non-cancer patients experience disadvantages in communication regarding their care and in access to specialized palliative care in their last year of life compared to cancer patients. Regarding the assessment of palliative care needs and the lack of communication of an incurable disease, non-cancer patients are underserved. An early identification of patients requiring palliative care is a major public health concern and should be addressed irrespective of diagnosis.
\end{abstract}

Trial registration Prospectively registered by the German Clinical Trials Register (DRKS00011925, data of registration: 13.06.2017).

Keywords Cancer $\cdot$ Non-cancer $\cdot$ Last year of life $\cdot$ VOICES questionnaire $\cdot$ End-of-life care $\cdot$ Proxy perspectives

Alina Kasdorf

alina.kasdorf@uk-koeln.de

1 Department of Palliative Medicine, Faculty of Medicine and University Hospital Cologne, University of Cologne, Cologne, Germany

2 Faculty of Medicine and University Hospital Cologne, Institute of Medical Statistics and Computational Biology, University of Cologne, Cologne, Germany

3 Department of Educational Science and Mixed-Methods-Research, Faculty of Educational and Social Sciences, University of Education Heidelberg, Heidelberg, Germany
4 Center for Health Services Research, Faculty of Medicine and University Hospital Cologne, University of Cologne, Cologne, Germany

5 Center for Integrated Oncology Aachen Bonn Cologne Dusseldorf (CIO ABCD), Faculty of Medicine and University Hospital Cologne, University of Cologne, Cologne, Germany

6 Clinical Trials Center (ZKS), Faculty of Medicine and University Hospital Cologne, University of Cologne, Cologne, Germany 


\section{Background}

Palliative care aims to improve the quality of life of patients facing multiple symptoms related to a life-threatening illness and that of their families, with particular emphasis being placed on the assessment and management of symptoms [1]. For some time, palliative care has mainly focused on the care of patients with cancer [2,3]. Currently, more attention has been devoted to introducing palliative care early in the trajectory disease in patients with non-malignant diagnoses [4]. Demographically, more than twice as many people die from non-malignant causes than from cancer [5]. Still, non-cancer diseases account for the lowest proportion of use in palliative care [6-8]. In Germany, specific data on the current situation of the two groups are hardly available. In the years between 2007 and 2011 , only $8.1 \%$ of all non-cancer patients received specialized palliative care [8]. Between 2014 and 2016, 80.5\% of all patients receiving specialized outpatient palliative care died from cancer [9]. Overall, 68-97\% of non-cancer patients have not received any palliative care services, compared to $50 \%$ of cancer patients [9]. In comparison, the percentage of non-cancer patients receiving hospice care in the USA was much higher (29.6\% in 2018) [10].

Often, the timing of referrals to palliative care for noncancer conditions is delayed $[7,11]$. Patients with nonmalignant disease have a less predictable course due to the frequent variability in the progression of their disease [12] and the lack of awareness of palliative care among caregivers and health professionals [13]. Recent findings in the study by Quinn et al. provide important data about the clinical benefits of palliative care in patients with noncancer diseases, showing that palliative care is associated with reduced acute care service use, mitigation of symptoms, and increased advance care planning in patients with non-cancer diseases [14].

Cancer and non-cancer patients experience some commonalities in symptom patterns and burden. These symptoms include pain, dyspnea, nausea and vomiting, anorexia, fatigue, anxiety, tension, and depression [15, 16]. Burt et al. [17] compared the experiences in the community in the last 3 months of life of older adults dying from cancer and non-cancer causes, using the Views of Informal Carers-Evaluation of Services (VOICES) [18]. These commonalities in the prevalence of problems across cancer- and non-cancer patients highlight the need for palliative care to be provided, irrespective of diagnosis [16].

To the best of our knowledge, the differences in health care provision between cancer and non-cancer patients in the last year of life in Germany have rarely been investigated. To address this research gap, the aim of our study was to evaluate the differences between cancer and non-cancer patients who have died in the region of Cologne, Germany.

\section{Methods}

This study is part of a project entitled the "Last Year of Life Study Cologne (LYOL-C)" [19]. A retrospective crosssectional survey of bereaved relatives representing decedents in the Cologne area (Germany) was conducted between November 2017 and August 2018. We included all relatives, friends, or volunteers if they were 18 years or older and had cared for a person in his/her last year of life (all will be referred to as "informants" hereafter). We excluded deaths in people under 18 years, as well as deaths by accident. The participants were recruited in cooperation with health and social care practitioners. Two recruitment strategies were used to identify potential participants: (i) questionnaire distribution through cooperating health and social care practitioners through client records by mail or personally and (ii) self-selection through public media (newspaper articles, flyers, and posters) [20].

A structured presentation of the last year of life in patients categorized in two groups supports this analysis, focusing on the most important checkpoints of health care provision in the last year of life [21]. Our analysis focuses on differences in communicating an incurable disease ("transition into the last year of life"); transitions across different health care settings in the last year of life; and general, palliative, and hospice care utilization, as well as place of death ("transition into death"). Ethical approval for the study was granted by the Ethics Committee of the University Hospital of Cologne (\#17-188). Relatives received written information about the study and data protection and had to give written informed consent for participation.

\section{Data collection}

A modified German version of the VOICES questionnaire (VOICES-LYOL-Cologne) [18, 19] was sent to sampled informants. VOICES-LYOL-Cologne is a validated survey with 106 items to assess the quality of care in the last year of life irrespective of diagnosis [20] We compared the last 12 months of life, irrespective of age. It is reasonable to consider 12 months before death, because the occurrence and intensity of multiple symptoms in cancer and non-cancer patients occurred equally in both disease groups near the end of life [22].

\section{Data analysis}

Statistical analyses were performed using IBM SPSS $\odot$ version 24.0 (IBM Corporation, Armonk, NY, USA). Patient 
characteristics are presented as mean \pm standard deviation (SD) or absolute and relative frequencies, respectively. The formation of groups (cancer vs. non-cancer) was based on the items categorizing the diagnosis of the participants. Differences in the reported experiences of cancer and noncancer decedents in the health care provision in the last year of life were assessed using a two-sided Pearson's chi-square test and the Mann-Whitney $U$ test. Presented $p$-values are two-sided and considered significant if $<5 \%$. All variables were summarized using descriptive statistics, with missing data excluded analyzing continuous and dichotomous variables. Due to the explorative character of this study and the small sample size, no adjustment of the significance level $\alpha$ was applied. The results are considered for exploratory purposes. To calculate the correlation coefficient $r$ for the Mann-Whitney $U$ test, the $z$-value and the sample size $(n)$ were used [23]. For the Pearson's chi-square test, Cramer's $V$ was reported.

\section{Results}

A pool of 351 participants was representative with respect to gender ( $47.9 \%$ male) and age ( $76.5 \pm 13.0$ years) compared with full data from Cologne (for more information, see Voltz et al. [20]). Characteristics of the patients and their informants divided in two groups are presented in Table 1.

There were 142 non-cancer patients and 209 cancer patients. Non-cancer patients were significantly older than cancer patients (non-cancer $84.2 \pm 9.64$ vs. cancer $71.3 \pm 12.4$ years; $p<0.001)$. Decedents dying of non-cancer causes were more likely to be female $(p=0.007$, Cramer's $V=0.151)$ and over 85 years $(p<0.001$; Cramer's $V=0.450$ ). Cancer patients were more likely to be male and under 85 years. Among the non-cancer-conditions, the main cause of death was due to neuropsychiatric disease clearly predominating by dementia with $40.8 \%$ (Parkinson's disease with $9.2 \%$, multiple sclerosis with $2.1 \%$, and amyotrophic lateral sclerosis with $2.1 \%$ ), followed by cardiovascular diseases, and disease of the respiratory system, as shown in Table 1. Most of the non-cancer patients had multiple comorbidities. According to the informants, $57.4 \%$ of non-cancer patients and $40.0 \%$ of cancer patients had been ill for less than 12 months ( $p=0.003$, Cramer's $V=0.169$ ).

\section{Transition into the last year of life}

In all, $60.2 \%(n=118)$ of non-cancer patients had not been told that their disease would lead to death, compared to $21.7 \%(n=198)$ of cancer patients $(p<0.001$, Cramer's $V=0.387$ ). Table 2 shows that one-fifth of non-cancer patients were told this information less than a month
Table 1 Characteristics of deceased patients and informants

\begin{tabular}{|c|c|c|}
\hline & $\begin{array}{l}\text { Non-cancer } \\
\%(n)\end{array}$ & $\begin{array}{l}\text { Cancer } \\
\%(n)\end{array}$ \\
\hline \multicolumn{3}{|l|}{ Deceased age at death (years) } \\
\hline $18-29$ & - & $0.5(1)$ \\
\hline $30-49$ & - & $2.9(6)$ \\
\hline $50-69$ & $7.7(11)$ & $39.2(82)$ \\
\hline $70-89$ & $59.9(85)$ & $51.7(108)$ \\
\hline $90+$ & $32.4(46)$ & $5.7(12)$ \\
\hline \multicolumn{3}{|l|}{ Deceased sex } \\
\hline Male & $38.7(55)$ & $54.1(113)$ \\
\hline Female & $61.3(87)$ & $45.9(96)$ \\
\hline \multicolumn{3}{|l|}{ Deceased ethnic group } \\
\hline German & 97.9 (139) & $96.2(201)$ \\
\hline Other & $2.1(3)$ & $3.8(8)$ \\
\hline \multicolumn{3}{|l|}{ Deceased family situation $^{\mathrm{a}}$} \\
\hline Had a partner & $29.8(42)$ & $57.9(121)$ \\
\hline Lived together with partner & $24.1(34)$ & $44.0(92)$ \\
\hline Had children & $48.9(69)$ & $47.4(99)$ \\
\hline Lived together with children & $9.9(14)$ & $8.6(18)$ \\
\hline Lived together with someone else & $9.9(14)$ & $3.3(7)$ \\
\hline Lived alone & $44.7(63)$ & $24.4(51)$ \\
\hline \multicolumn{3}{|l|}{ Someone else had power of attorney } \\
\hline Yes & $90.8(129)$ & $87.1(182)$ \\
\hline No & $7.7(11)$ & $10.5(22)$ \\
\hline Do not know & $1.4(2)$ & $2.4(5)$ \\
\hline \multicolumn{3}{|l|}{ Illnesses in the last year of life $\mathrm{e}^{\mathrm{a}}$} \\
\hline Cardiovascular disease & $61.3(87)$ & $26.3(55)$ \\
\hline Neuropsychiatric disease & $63.4(90)$ & $12.0(25)$ \\
\hline Disease of the respiratory system & $43.7(62)$ & $19.6(41)$ \\
\hline Liver or kidney disease & $25.4(36)$ & $12.9(27)$ \\
\hline Diabetes mellitus & $16.2(23)$ & $10.5(22)$ \\
\hline Multimorbidity & $78.0(110)$ & $49.3(103)$ \\
\hline \multicolumn{3}{|l|}{ Informant relation to deceased } \\
\hline Spouse & $23.2(33)$ & $55.5(116)$ \\
\hline Son/daughter & $56.3(80)$ & $27.8(58)$ \\
\hline Sibling & $3.5(5)$ & $6.2(13)$ \\
\hline Son/daughter-in-law & $4.2(6)$ & $1.4(3)$ \\
\hline Parent & $0.7(1)$ & $1.0(2)$ \\
\hline Other relative & $8.5(12)$ & $1.0(2)$ \\
\hline Friend & $2.1(3)$ & $4.3(9)$ \\
\hline Neighbor & - & $0.5(1)$ \\
\hline Volunteer & - & $1.0(2)$ \\
\hline Other & $1.4(2)$ & $1.4(3)$ \\
\hline \multicolumn{3}{|l|}{ Informant age (years) } \\
\hline $18-29$ & - & $1.0(2)$ \\
\hline $30-49$ & $9.2(13)$ & $15.8(33)$ \\
\hline $50-69$ & $66.2(94)$ & $56.0(117)$ \\
\hline $70-89$ & $23.9(34)$ & $26.8(56)$ \\
\hline $90+$ & $0.7(1)$ & $0.5(1)$ \\
\hline \multicolumn{3}{|l|}{ Informant sex } \\
\hline Male & $21.1(30)$ & $33.5(70)$ \\
\hline Female & $78.9(112)$ & $66.5(139)$ \\
\hline
\end{tabular}

${ }^{\mathrm{a}}$ Multiple responses were possible 
Table 2 How long before death was he/she told that the disease would lead to death?

\begin{tabular}{lll}
\hline & Non-cancer $(n=45)$ & Cancer $(n=148)$ \\
\hline Less than 1 week & $11.1(5)$ & $6.8(10)$ \\
At least 1 week but less than 1 month & $11.1(5)$ & $16.2(24)$ \\
At least 1 month but less than 6 months & $35.6(16)$ & $22.3(33)$ \\
At least 6 months but less than 1 year & $11.1(5)$ & $21.6(32)$ \\
1 year or longer & $31.1(14)$ & $33.1(49)$ \\
\hline
\end{tabular}

Data are presented as $\%(n)$ before death. The information about death being imminent was given to $33.1 \%$ of non-cancer patients and $58.4 \%$ of cancer patients $(p<0.001$, Cramer's $V=0.249)$.

Table 3 shows that hospital doctors are predominantly delivering bad news to both groups of patients. Second most frequent, general practitioners (GPs) are mostly informing non-cancer patients that the disease leads to death, while outpatient specialist physicians are mostly informing cancer patients about their approaching death.

\section{Transitions within the last year of life}

Table 4 shows that more than nine out of 10 non-cancer patients were predominantly treated by a GP or cared for by

Table 3 Who told that the disease would lead to death?

\begin{tabular}{|c|c|c|c|c|}
\hline & Non-cancer & Cancer & $p$ & Cramer's V \\
\hline Hospital doctor & $46.7(21)$ & $64.5(91)$ & 0.050 & 0.156 \\
\hline $\begin{array}{l}\text { Outpatient specialist } \\
\text { physician }\end{array}$ & $8.9(4)$ & $17.7(25)$ & n. $s$ & n. $s$ \\
\hline General practitioner & $17.8(8)$ & $5.0(7)$ & 0.015 & 0.202 \\
\hline Close relatives/friends & $17.8(8)$ & $9.9(14)$ & n. $s$ & n. $s$ \\
\hline Someone else & $8.9(4)$ & $2.8(4)$ & n. $s$ & n. $s$ \\
\hline
\end{tabular}

Data are presented as \% $(n)$. Presented $p$-values are from Pearson's chi square test a nursing home in their last year of life, while cancer patients were more often treated by an outpatient specialist physician.

Overall, at least one member/setting of general or specialized palliative care was involved in the last year of life with $39.4 \%$ of non-cancer patients and $85.6 \%$ of cancer patients ( $p<0.001$; Cramer's $V=0.482)$, which corresponds to a strong effect.

Regarding the last hospital stay, $20.8 \%$ of non-cancer patients and $11.3 \%$ of cancer patients predominantly spent their time in an intensive care unit $(p=0.033$; Cramer's $V=0.129$ ). Furthermore, cancer patients are predominantly cared for by a palliative care team (cancer $43.8 \%$ vs. non-cancer $4.2 \%$; $p<0.001$, Cramer's $V=0.426$ ).

As shown in Table 5, non-cancer patients experienced significantly fewer transitions between care settings and hospital stays in their last year of life than cancer patients. Also, in the last month of life, non-cancer patients had significantly fewer transitions.

\section{Transition into death}

Data showed that $35.9 \%$ of non-cancer patients and $46.6 \%$ of cancer patients died in acute care hospitals, with non-cancer patients predominantly dying in the general or intensive care unit (non-cancer $28.9 \%$ vs. cancer $13.5 \%$; $p=0.001$, Cramer's $V=0.190$ ). Nearly five times as many cancer patients died in hospice, while most non-cancer deaths occurred in the nursing home (Table 6).
Table 4 Health care provider in the last year of life

\begin{tabular}{lllll}
\hline & Non-cancer & Cancer & $p$ & Cramer's V \\
\hline General practitioner & $95.0(134)$ & $83.4(171)$ & 0.002 & 0.177 \\
Outpatient specialist physician & $69.3(97)$ & $84.0(173)$ & 0.002 & 0.174 \\
Specialist palliative home care team & $22.9(32)$ & $50.0(103)$ & $<0.001$ & 0.273 \\
Outpatient care service & $48.2(67)$ & $43.5(90)$ & n. s & n. s \\
Hospice & $5.2(7)$ & $27.8(57)$ & $<0.001$ & 0.283 \\
Nursing home & $43.2(60)$ & $7.7(15)$ & $<0.001$ & 0.419 \\
Outpatient hospice service & $5.7(8)$ & $7.2(15)$ & n. s & n. s \\
\hline
\end{tabular}

Data are presented as \% $(n)$. Presented $p$-values are from Pearson's chi-square test 
Table 5 Transitions in the last year of life

\begin{tabular}{|c|c|c|c|c|}
\hline & Non-cancer $(n=102)$ & Cancer $(n=153)$ & $p$ & $r$ \\
\hline \multicolumn{5}{|c|}{ Hospital admissions in the last... } \\
\hline Month & $0.44 \pm 0.57$ & $0.62 \pm 0.65$ & 0.027 & 0.14 \\
\hline 3 months & $1.04 \pm 0.95$ & $1.27 \pm 1.05$ & n. $s$ & n. s \\
\hline 6 months & $1.37 \pm 1.23$ & $1.72 \pm 1.44$ & n. $s$ & n. $s$ \\
\hline 9 months & $1.59 \pm 1.44$ & $1.98 \pm 1.57$ & 0.037 & 0.13 \\
\hline 12 months & $1.69 \pm 1.58$ & $2.22 \pm 1.71$ & 0.007 & 0.17 \\
\hline \multicolumn{5}{|c|}{ Hospital stays in the last... } \\
\hline Month & $0.68 \pm 0.75$ & $0.85 \pm 0.78$ & n. $s$ & n. s \\
\hline 3 months & $1.10 \pm 0.96$ & $1.37 \pm 1.13$ & n. $s$ & n. $\mathrm{s}$ \\
\hline 6 months & $1.45 \pm 1.27$ & $1.76 \pm 1.46$ & n. $\mathrm{s}$ & n. $\mathrm{s}$ \\
\hline 9 months & $1.66 \pm 1.52$ & $2.01 \pm 1.56$ & 0.048 & 0.12 \\
\hline 12 months & $1.73 \pm 1.61$ & $2.24 \pm 1.73$ & 0.008 & 0.17 \\
\hline \multicolumn{5}{|c|}{ Transitions in the last... } \\
\hline Month & $0.75 \pm 0.90$ & $0.99 \pm 0.93$ & 0.021 & 0.14 \\
\hline 3 months & $1.77 \pm 1.54$ & $2.18 \pm 1.71$ & n. $\mathrm{s}$ & n. $s$ \\
\hline 6 months & $2.49 \pm 2.12$ & $3.09 \pm 2.63$ & n. $s$ & n. $s$ \\
\hline 9 months & $2.94 \pm 2.59$ & $3.65 \pm 2.90$ & 0.047 & 0.12 \\
\hline 12 months & $3.15 \pm 2.80$ & $4.10 \pm 3.25$ & 0.014 & 0.15 \\
\hline
\end{tabular}

Data are presented as mean \pm standard deviation. Presented $p$-values are from the Mann-Whitney $U$ test. For calculating the correlation coefficient $r$, the z-value and sample size $(n)$ were used

Table 6 Place of death

\begin{tabular}{lllll}
\hline & Non-cancer & Cancer & $p$ & Cramer's V \\
\hline At home & $32.4(46)$ & $24.5(51)$ & n. s & n. s \\
Hospital & $35.9(51)$ & $46.6(97)$ & n. s & n. s \\
Hospice & $4.9(7)$ & $26.0(54)$ & $<0.001$ & 0.272 \\
Nursing home & $24.6(35)$ & $2.9(6)$ & $<0.001$ & 0.332 \\
Other & $2.1(3)$ & $0.5(0)$ & n. s & n. s \\
\hline
\end{tabular}

Data are presented as \% (n). Presented $p$-values are from Pearson's chi square test

\section{Discussion}

\section{Main findings}

This study analyzed the possible differences between patients with cancer and non-cancer conditions in their last year of life according to transitions, communication, generalist or palliative and hospice care utilization, and place of death in Germany.
Although communication about the course of disease is an extremely important element of adequate care, noncancer patients were informed less often about their incurable disease than cancer patients. Only four out of 10 noncancer patients were entering the last year of life knowing about the lethality of their disease. Non-cancer patients were also less often informed about imminent death than cancer patients.

Our results show that GPs mainly treated non-cancer patients, while cancer patients were mostly consulting an outpatient specialist physician and being treated by palliative care specialists. Interestingly, most often, GPs were the ones who told non-cancer patients that their disease would lead to death, while cancer patients were informed by an outpatient specialist physician. In the literature, GPs discussed significantly more frequently all end-of-life issues, although these were discussed significantly more frequently with cancer patients than with non-cancer patients [24]. The low rate of information by the GPs about the trajectory of the disease, and end-of-life care, could be due to several factors: GP lack of availability (lack of time, absence or not making home visits) and the ambivalence of patients and GPs to discuss a "bad diagnosis" [25]. In Germany, the need for strengthening the collaboration between primary health care providers and specialist palliative care services has already been communicated by previous research [13]. The role of GPs is a significant one (e.g., initiating palliative care for non-cancer patients). Afshar et al. reported that non-cancer patients are predominately cared for by generalist palliative care and describe an urgent need to enhance interprofessional and interdisciplinary work between different health care professionals [26]. As GPs were identified as the major health care providers for non-cancer patients, the aim of future studies should be to determine the role of GPs as gatekeepers for referral in the of non-cancer patients to specialized palliative care teams.

The qualifications of the health care professionals also play a role in the initiation into palliative care structures. There is a need for improvement in the integration of palliative care into education of education and training to increase the proportion of specialist physicians and GPs with advanced training in palliative care in Germany, which is currently too low [27].

It has already been postulated at an international level that palliative care must be offered on a non-indication-specific basis $[3,16]$. Both patient groups can essentially benefit from early integration of palliative care [28]. According to estimates, between 40.7 and $96.1 \%$ of deaths would benefit from palliative care, regardless of the indication [29]. One in five cancer patients requires specialized palliative care [30]. By adding non-cancer patients to this group, a 79\% increase in specialized palliative care services caseload can be expected [3]. 
Non-cancer patients were identified by German health care experts as target groups with a particular priority for palliative care [31]. There is still an asymmetric distribution of palliative care in non-cancer patients. Regarding the use of palliative care structures, our data show these are still mainly used by cancer patients (such as primary palliative care or specialized outpatient palliative care). Non-cancer patients were also under-represented in hospice, were less likely to receive outpatient hospice services and less likely to be treated in a hospital palliative ward, but more likely to be cared for in a nursing home or in an intensive care unit. Existing literature confirms that non-cancer patients are using hospice services less often than cancer patients [32]. Additionally, non-cancer patients are more frequently treated in an ICU [33].

Despite the higher probability of having been informed about the lethality of the disease, cancer patients have more transitions in their last year of life than non-cancer patients. A systematic review demonstrated that the use of specialized palliative care is associated with a reduction of hospital admissions for cancer patients [34], while our results assume the opposite. The reason for this could be oncological therapies and potential complications of cancer patients necessitating more transitions, while non-cancer patients and health care professionals have more uncertainty about their diagnosis [35], resulting from the unpredictability of the course of disease. In general, non-cancer patients had a longer time course with a much slower and unpredictable decline, allowing services to be organized more easily in the longer timeline available [35]. Also, a lack of written referral policy guidelines, unpredictable course of non-cancer disease, subsequent difficulties with developing referral criteria, and the lack of non-cancer-specific expertise must be considered [36]. With regard to hospitalization in the last month of life, the results of this study differ from previous evidence. Hospital admissions were more frequent in patients with cancer, while other studies indicated that non-cancer patients are hospitalized more often [37]. A link to the country-specific health care system could be assumed for the results of this study.

Previous research indicates people dying from cancer were less likely to die in a hospital than at home [38]. In most populations, the proportion of home deaths [39] and nursing home deaths [40] was higher in patients with cancer than those without. Our data have not confirmed these results. Non-cancer patients were more likely to die in a care home, while cancer patients were more likely to die in hospice. Cancer deaths were strongly associated with the probability of dying in a hospice in other research [40]. Regarding other places of death, no statistically significant differences were found.

Overall, regarding the assessment of palliative care needs and the partial lack of communication of an incurable disease, non-cancer patients are at a particular disadvantage compared to cancer patients. The unpredictability of disease progression and the estimation of prognosis in nonmalignant diseases is used as an explanation for the clear underrepresentation of non-cancer patients in palliative care. Clinicians find it challenging to know when patients should be referred to palliative care $[8,16]$. A considerable proportion of non-cancer patients had neurological diseases. This highlights the challenge to integrate palliative care for these patient groups, especially for those with, e.g., dementia, multiple sclerosis, or Parkinson's disease, who still "fall through the net" and do not receive the holistic care that they need [41, 42]. For neurological diseases in particular, the unpredictable course of the disease, long periods of care, and, in some cases, a lack of information about the roles and services of palliative care among health care providers constitute major obstacles to engage palliative care [43]. It is also particularly important to support the informal carers, some of whom have been caring for the patients for years. Most of non-cancer patients in this sample turned over 80 , which is not solely due to dementia patients. CHD patients are also older in our sample. We hypothesize that older patients are more vulnerable to experiencing a complex interplay of multiple problems and symptoms in different domains, concerning not only the physical but also the psychological, social, and functional domains [22]. Due to the changes in physiology related to the aging process and the higher prevalence of multimorbidity in this population, we think that these issues might explain a difference in age here.

Despite these challenges, health professionals should be made aware of the need to refer patients to palliative care at an early stage of their care parallel to the standard treatment, based on the needs of patients [22]. Differences in referral criteria and lack of specific expertise may be possible obstacles to the provision of care for non-cancer patients [36]. The difficulties of identifying palliative care needs have been addressed in the previous literature [44], especially for neurodegenerative conditions [42]. Numerous instruments are available to support the identification of both disease groups. A routine use of instruments for proactive identification of patients in their last year of life is recommended, addressing the need for earlier referral to palliative care [26, 45]. It is important to consider the prognostic quality in assessing the expected survival of non-cancer patients, due to the unpredictable nature of non-malignant diseases [46]. Furthermore, systematic and diagnosis-independent consideration and initiation of palliative care options in clinical practice are required [47].

\section{Strengths and limitations}

To the best of our knowledge, there is no analysis of the health care provision in the last year of life in a German urban area with advanced palliative care consultation service 
and dedicated hospice care structure to date. This paper provides exploratory insight into the differences in care for patients who have died of cancer and non-cancer. Further research is necessary to examine the effects confirmatively. The retrospective proxy design seems appropriate for this type of research [48]. The data from the survey remain relevant and current at the present time, as there have been no legislative amendments since the 2015 Act to improve Hospice and Palliative Care in Germany [49]. The law is intended to provide better access for all terminal illnesses.

The retrospective classification into the examination group was based on the primary diagnosis. It cannot be excluded that patients with a malignant diagnosis, who have heart failure triggering the severe symptoms were classified into the cancer patient group. It was also not known what reasons caused each transition between the health care settings, so it was not possible to directly compare these transitions.

A further potential limitation might lie in the comparisons of the specific features of the German health care system, since some results are not transferable. In addition, the data generated here came from a large German city. Therefore, no statement can be made about rural regions. Existing evidence has so far been consistent in showing a disparity in palliative care of cancer and non-cancer patients [7, 14]. These results are also limited to people with caregivers/relatives. It also must be considered that an opt-in-research format in general could be seen as a confounder, so we were only able to gain insights into the care experiences of relatives who actively consented.

\section{Conclusions/implications for practice}

For the non-cancer patient group, a clear disadvantage was identified, including the gap in access to palliative care and the lack of communication around prognosis, including the information about the imminent death. The results underline the importance of early integration of palliative care for patient groups with non-malignant diseases, reconsidering the need for disease-modifying treatment strategies. Furthermore, since GPs have been identified as key health care providers for the non-cancer patients and access to palliative care is still limited for this patient population, it will be important for both GPs and outpatient disease-specific specialist physicians to avoid fragmentation of care by communicating relevant patient information. And thus achieving higher quality of end-of-life care for patients and their relatives. A further study is needed to explore why the associated specialists (neurology, nephrology, cardiology, respiratory, etc.) are not sufficiently engaged in conversations with their patients in their last months of life. While the GP may know the patient better, or longer, it is the specialist that may need to answer disease-specific questions and provide prognosis.
Acknowledgements The authors wish to thank all participants for their contribution and the German Federal Ministry of Education and Research (BMBF) for funding this study.

Collaborators The CoRe-Net Co-applicants: Professor Dr Holger Pfaff, Faculty of Human Sciences and Faculty of Medicine, Institute for Medical Sociology, Health Services Research, and Rehabilitation Science, University of Cologne, Professor Dr Christian Albus, Department of Psychosomatics and Psychotherapy, Faculty of Medicine (FM), University Hospital Cologne (UHC); Professor Dr Lena Ansmann, Department of Health Services Research, School of Medicine and Health Sciences, Carl von Ossietzky University Oldenburg; Professor Dr Frank Jessen, Department of Psychiatry and Psychotherapy, FM, UHC; Professor Dr Ute Karbach, Sociology in Rehabilitation, Faculty of Rehabilitation, Technical University Dortmund; Professor Dr Ludwig Kuntz, Department of Business Administration and Health Care Management, Faculty of Management, Economics and Social Sciences (FMESS), University of Cologne (UoC); Dr Ingrid Schubert, PMV Health Care Research Group, FM, UoC; Professor Dr Frank SchulzNieswandt, Institute for Sociology and Social Psychology, FMESS, UoC; Professor Dr Stephanie Stock, Institute for Health Economics and Clinical Epidemiology, FM, UHC.

Author contribution $\mathrm{AK}$ is the first author and acts as guarantor. RV, JS, and CR are principal investigators and responsible for the study design, project management, data analysis, and dissemination. GD and $\mathrm{NiS}$ designed the survey instrument and collected the data. AK analyzed and interpreted the data. JS, RV, CR, NiS, SH, and GD reviewed and commented drafts of the manuscript. All authors read and approved the final manuscript.

Funding Open Access funding enabled and organized by Projekt DEAL. This research was supported by the German Federal Ministry of Education and Research (BMBF), grant number \#01GY1606.

Availability of data and material The datasets used and/or analyzed during the current study are available from the corresponding author on reasonable request.

Code availability Not applicable.

\section{Declarations}

Ethics approval The study was performed in line with the principles of the Declaration of Helsinki and was approved by the Ethics Commission of the Faculty of Medicine of Cologne University on December 2017 (\#17-188).

Consent to participate Participants gave written informed consent before taking part.

Consent for publication Not applicable.

Conflict of interest The authors declare no competing interests.

Open Access This article is licensed under a Creative Commons Attribution 4.0 International License, which permits use, sharing, adaptation, distribution and reproduction in any medium or format, as long as you give appropriate credit to the original author(s) and the source, provide a link to the Creative Commons licence, and indicate if changes were made. The images or other third party material in this article are included in the article's Creative Commons licence, unless indicated otherwise in a credit line to the material. If material is not included in 
the article's Creative Commons licence and your intended use is not permitted by statutory regulation or exceeds the permitted use, you will need to obtain permission directly from the copyright holder. To view a copy of this licence, visit http://creativecommons.org/licenses/by/4.0/.

\section{References}

1. World Health Organization. Definition of palliative care. https://www. who.int/cancer/palliative/definition/en/. Accessed 25 Aug 2020

2. Bostwick D, Wolf S, Samsa G et al (2017) Comparing the palliative care needs of those with cancer to those with common noncancer serious illness. J Pain Symptom Manag 53(6):1079-1084. e1. https://doi.org/10.1016/j.jpainsymman.2017.02.014

3. Addington-Hall J, Fakhoury W, McCarthy M (1998) Specialist palliative care in nonmalignant disease. Palliat Med 12(6):417427. https://doi.org/10.1191/026921698676924076

4. Boland J, Johnson MJ (2013) End-of-life care for non-cancer patients. BMJ Support Palliat Care 3(1):2-3. https://doi.org/10. 1136/bmjspcare-2013-000446

5. Solano JP, Gomes B, Higginson IJ (2006) A comparison of symptom prevalence in far advanced cancer, AIDS, heart disease, chronic obstructive pulmonary disease and renal disease. J Pain Symptom Manage 31(1):58-69. https://doi.org/10.1016/j.jpain symman.2005.06.007

6. Radbruch L, Andersohn F, Walker J (2015) Überversorgung kurativ-Unterversorgung palliativ?: Analyse ausgewählter Behandlungen am Lebensende. Faktencheck Gesundheit. Gütersloh, Bertelsmann-Stiftung

7. Ostgathe C, Alt-Epping B, Golla H et al (2011) Non-cancer patients in specialized palliative care in Germany: what are the problems? Palliat Med 25(2):148-152. https://doi.org/10.1177/ 0269216310385370

8. Hess S, Stiel S, Hofmann S et al (2014) Trends in specialized palliative care for non-cancer patients in Germany-data from the national hospice and palliative care evaluation (HOPE). Eur $\mathbf{J}$ Intern Med 25(2):187-192. https://doi.org/10.1016/j.ejim.2013. 11.012

9. Krumm N, Rolke R (2020) Evaluation der Wirksamkeit von SAPV in Nordrhein. Ergebnisbericht. In: Gemeinsamer Bundesausschuss

10. NHPCO (2020) NHPCO facts and figures:. 2020 Edition. https:// www.nhpco.org/wp-content/uploads/NHPCO-Facts-Figures2020-edition.pdf. Accessed 01 Jul 2021

11. Gadoud A, Kane E, Oliver SE et al (2020) Palliative care for noncancer conditions in primary care: a time trend analysis in the UK (2009-2014). BMJ Support Palliat Care. https://doi.org/10.1136/ bmjspcare-2019-001833

12. Murray SA, Kendall M, Boyd K et al (2005) Illness trajectories and palliative care. BMJ 330(7498):1007-1011. https://doi.org/ 10.1136/bmj.330.7498.1007

13. Behmann M, Jünger S, Radbruch L et al (2012) Public health actions to improve palliative care in Germany: results of a threeround Delphi study. Health Policy (Amsterdam, Netherlands) 106(3):303-312. https://doi.org/10.1016/j.healthpol.2012.03.014

14. Quinn KL, Wegier P, Stukel TA et al (2021) Comparison of palliative care delivery in the last year of life between adults with terminal noncancer illness or cancer. JAMA Netw Open 4(3):e210677. https://doi.org/10.1001/jamanetworkopen.2021.0677

15. Stiel S, Matthies DMK, Seuß D et al (2014) Symptoms and problem clusters in cancer and non-cancer patients in specialized palliative care-is there a difference? J Pain Symptom Manag 48(1):26-35. https://doi.org/10.1016/j.jpainsymman. 2013.08.018
16. Moens K, Higginson IJ, Harding R (2014) Are there differences in the prevalence of palliative care-related problems in people living with advanced cancer and eight non-cancer conditions? A systematic review. J Pain Symptom Manag 48(4):660-677. https:// doi.org/10.1016/j.jpainsymman.2013.11.009

17. Burt J, Shipman C, Richardson A et al (2010) The experiences of older adults in the community dying from cancer and noncancer causes: a national survey of bereaved relatives. Age Ageing 39(1):86-91. https://doi.org/10.1093/ageing/afp212

18. Hunt KJ, Richardson A, Darlington A-SE et al (2019) Developing the methods and questionnaire (VOICES-SF) for a national retrospective mortality follow-back survey of palliative and end-of-life care in England. BMJ Support Palliat Care 9(1):e5. https://doi.org/ 10.1136/bmjspcare-2016-001288

19. Strupp J, Hanke G, Schippel N et al (2018) Last Year of Life Study Cologne (LYOL-C): protocol for a cross-sectional mixed methods study to examine care trajectories and transitions in the last year of life until death. BMJ Open 8(4):e021211. https://doi.org/10.1136/ bmjopen-2017-021211

20. Voltz R, Dust G, Schippel $\mathrm{N}$ et al. Improving regional care in the last year of life by setting up a Improving regional care in the last year of life by setting up a pragmatic evidence-based Plan-DoStudy-Act cycle: Results from a cross sectional survey. BMJ open

21. Lendon JP, Ahluwalia SC, Walling AM et al (2015) Measuring experience with end-of-life care: a systematic literature review. J Pain Symptom Manag 49(5):904-15.e1-3. https://doi.org/10. 1016/j.jpainsymman.2014.10.018

22. van Lancker A, van Hecke A, Verhaeghe S et al (2018) A comparison of symptoms in older hospitalised cancer and non-cancer patients in need of palliative care: a secondary analysis of two cross-sectional studies. BMC Geriatr 18(1):40. https://doi.org/10. 1186/s12877-018-0721-7

23. Cohen J (1992) Statistical power analysis. Curr Dir Psychol Sci 1(3):98-101. https://doi.org/10.1111/1467-8721.ep10768783

24. Abarshi E, Echteld M, Donker G et al (2011) Discussing end-oflife issues in the last months of life: a nationwide study among general practitioners. J Palliat Med 14(3):323-330. https://doi.org/ 10.1089/jpm.2010.0312

25. Slort W, Schweitzer BPM, Blankenstein AH et al (2011) Perceived barriers and facilitators for general practitioner-patient communication in palliative care: a systematic review. Palliat Med 25(6):613-629. https://doi.org/10.1177/0269216310395987

26. Afshar K, Geiger K, Müller-Mundt G et al (2015) Generalist palliative care for non-cancer patients. Schmerz (Berlin, Germany) 29(6):604-615. https://doi.org/10.1007/s00482-015-0054-9

27. Kasdorf A, Dust G, Vennedey V et al (2021) What are the risk factors for avoidable transitions in the last year of life? A qualitative exploration of professionals' perspectives for improving care in Germany. BMC Health Serv Res 21(1):147. https://doi.org/10. 1186/s12913-021-06138-4

28. Bakitas M, Lyons KD, Hegel MT et al (2009) Effects of a palliative care intervention on clinical outcomes in patients with advanced cancer: the Project ENABLE II randomized controlled trial. JAMA 302(7):741-749. https://doi.org/10.1001/jama.2009. 1198

29. Scholten N, Günther AL, Pfaff H et al (2016) The size of the population potentially in need of palliative care in Germany-an estimation based on death registration data. BMC Palliat Care 15:29. https://doi.org/10.1186/s12904-016-0099-2

30. Dasch B, Blum K, Bausewein C (2017) Abschätzung des ambulanten palliativmedizinischen Versorgungsgrades regionaler palliativmedizinischer Konsiliardienste in Westfalen-Lippe. Gesundheitswesen (Bundesverband der Arzte des Offentlichen Gesundheitsdienstes (Germany)) 79(12): 1036-1042. https://doi. org/10.1055/s-0041-110529 
31. Behmann M, Lückmann SL, Schneider N (2009) Palliative care in Germany from a public health perspective: qualitative expert interviews. BMC Res Notes 2:116. https://doi.org/10.1186/ 1756-0500-2-116

32. Tobin J, Rogers A, Winterburn I et al (2021) Hospice care access inequalities: a systematic review and narrative synthesis. BMJ Support Palliat Care. https://doi.org/10.1136/bmjsp care-2020-002719

33. Lyngaa $\mathrm{T}$, Christiansen $\mathrm{CF}$, Nielsen $\mathrm{H}$ et al (2015) Intensive care at the end of life in patients dying due to non-cancer chronic diseases versus cancer: a nationwide study in Denmark. Crit Care (London, England) 19:413. https://doi.org/10.1186/s13054-015-1124-1

34 Higginson IJ, Evans CJ (2010) What is the evidence that palliative care teams improve outcomes for cancer patients and their families? Cancer J (Sudbury, Mass.) 16(5):423-435. https://doi. org/10.1097/PPO.0b013e3181f684e5

35. Lawson B, Burge FI, Critchley P et al (2006) Factors associated with multiple transitions in care during the end of life following enrollment in a comprehensive palliative care program. BMC Palliat Care 5:4. https://doi.org/10.1186/1472-684X-5-4

36. O'Leary N, Tiernan E (2008) Survey of specialist palliative care services for noncancer patients in Ireland and perceived barriers. Palliat Med 22(1):77-83. https://doi.org/10.1177/0269216307 084609

37. Lau KS, Tse DMW, Tsan Chen TW et al (2010) Comparing noncancer and cancer deaths in Hong Kong: a retrospective review. J Pain Symptom Manag 40(5):704-714. https://doi.org/10.1016/j. jpainsymman.2010.02.023

38. Evans CJ, Ho Y, Daveson BA et al (2014) Place and cause of death in centenarians: a population-based observational study in England, 2001 to 2010. PLoS Med 11(6):e1001653. https://doi. org/10.1371/journal.pmed.1001653

39. Cohen J, Houttekier D, Onwuteaka-Philipsen B et al (2010) Which patients with cancer die at home? A study of six European countries using death certificate data. J Clin Oncol 28(13):2267-2273. https://doi.org/10.1200/JCO.2009.23.2850

40. Dasch B, Blum K, Gude P et al (2015) Place of death: trends over the course of a decade: a population-based study of death certificates from the years 2001 and 2011. Deutsches Arzteblatt Int 112(29-30):496-504. https://doi.org/10.3238/arztebl.2015.0496

41. Klietz M, Tulke A, Müschen LH et al (2018) Impaired quality of life and need for palliative care in a German cohort of advanced
Parkinson's disease patients. Front Neurol 9. https://doi.org/10. 3389/fneur.2018.00120

42. Browne B, Kupeli N, Moore KJ et al (2021) Defining end of life in dementia: a systematic review. Palliat Med 35(10):1733-1746. https://doi.org/10.1177/02692163211025457

43. Strupp J, Voltz R, Golla H (2016) Opening locked doors: Integrating a palliative care approach into the management of patients with severe multiple sclerosis. Multiple Sclerosis (Houndmills, Basingstoke, England) 22(1):13-18. https://doi.org/10.1177/ 1352458515608262

44. ElMokhallalati Y, Bradley SH, Chapman E et al (2020) Identification of patients with potential palliative care needs: a systematic review of screening tools in primary care. Palliat Med 34(8):9891005. https://doi.org/10.1177/0269216320929552

45. Yarnell CJ, Jewell LM, Astell A et al (2021) Observational study of agreement between attending and trainee physicians on the surprise question: "Would you be surprised if this patient died in the next 12 months?" PLoS ONE 16(2):e0247571. https://doi.org/ 10.1371/journal.pone.0247571

46. Coventry PA, Grande GE, Richards DA et al (2005) Prediction of appropriate timing of palliative care for older adults with nonmalignant life-threatening disease: a systematic review. Age Ageing 34(3):218-227. https://doi.org/10.1093/ageing/afi054

47. To THM, Greene AG, Agar MR et al (2011) A point prevalence survey of hospital inpatients to define the proportion with palliation as the primary goal of care and the need for specialist palliative care. Intern Med J 41(5):430-433. https://doi.org/10.1111/j. 1445-5994.2011.02484.x

48. McPherson CJ, Addington-Hall JM (2003) Judging the quality of care at the end of life: can proxies provide reliable information? Soc Sci Med 56(1):95-109. https://doi.org/10.1016/S02779536(02)00011-4

49. Der Bundestag (2015) Gesetz zur Verbesserung der Hospiz- und Palliativversorgung in Deutschland (Hospiz- und Palliativgesetz - HPG). HPG

Publisher's note Springer Nature remains neutral with regard to jurisdictional claims in published maps and institutional affiliations. 